\title{
BMJ Open Antibiotic stewardship in skin infections: a cross-sectional analysis of early-career GP's management of impetigo
}

\author{
Clare Heal, ${ }^{1}$ Hilary Gorges (D) ,2 Mieke L van Driel (D) , ${ }^{3}$ Amanda Tapley, ${ }^{4,5}$ \\ Josh Davis, ${ }^{6}$ Andrew Davey, ${ }^{7}$ L Holliday, ${ }^{8}$ Jean Ball, ${ }^{9}$ Nashwa Najib, ${ }^{7}$ Neil Spike, ${ }^{10,11}$ \\ Kristen FitzGerald, ${ }^{12}$ Parker Magin (i) ${ }^{13}$
}

To cite: Heal C, Gorges $\mathrm{H}$, van Driel ML, et al. Antibiotic stewardship in skin infections: a cross-sectional analysis of early-career GP's management of impetigo. BMJ Open 2019;9:e031527. doi:10.1136/ bmjopen-2019-031527

- Prepublication history for this paper is available online. To view these files, please visit the journal online (http://dx.doi. org/10.1136/bmjopen-2019031527).

Received 08 May 2019 Revised 12 July 2019 Accepted 23 August 2019

Check for updates

(C) Author(s) (or their employer(s)) 2019. Re-use permitted under CC BY-NC. No commercial re-use. See rights and permissions. Published by BMJ.

For numbered affiliations see end of article.

Correspondence to

Dr Clare Heal;

Clare.Heal@jcu.edu.au

\section{ABSTRACT}

Objective To establish the prevalence and associations of systemic antibiotic prescription for impetigo by earlycareer general practitioners (GPS) (GP registrars in their first 18 months in general practice).

Design A cross-sectional analysis of data from the Registrar Clinical Encounters in Training (ReCEnT) study. Setting ReCEnT is an ongoing multisite cohort study of Australian registrars' in-consultation clinical practice across five Australian states.

Participants Registrars participating in ReCEnT from 2010 to 2017.

Outcome measures Management of impetigo with systemic antibiotics.

Results 1741 registrars (response rate 96\%) provided data from 384731 problems identified in 246434 consultations. Impetigo, on first presentation or followup, was managed in $930(0.38 \%, 95 \% \mathrm{Cl} 0.35$ to 0.40$)$ consultations and comprised $0.24 \%$ ( $95 \% \mathrm{Cl} 0.23$ to 0.26 ) of problems. 683 patients presented with a new diagnosis of impetigo of which $38 / 683$ (5.6\%) were not prescribed antibiotics; 239/683 (35.0\%) were prescribed solely topical antibiotics; $306 / 683(44.8 \%)$ solely systemic antibiotics and 100/683 (14.6\%) both systemic and topical antibiotics. The most common systemic antibiotic prescribed was cephalexin (53.5\%). Variables independently associated with prescription of systemic antibiotics were an inner regional (compared with major city) location (OR 1.82, $95 \% \mathrm{Cl} 1.06$ to $3.13 ; p=0.028$ ), seeking in-consultation information or advice (OR 2.17, 95\% Cl 1.47 to 3.23 ; $\mathrm{p}<0.001)$ and ordering pathology $(0 \mathrm{R} 2.13,95 \% \mathrm{Cl} 1.37$ to 3.33; $p=0.01$ ).

Conclusions Australian early-career GPs prescribe systemic antibiotics (the majority broad-spectrum) for a high proportion of initial impetigo presentations. Impetigo guidelines should clearly specify criteria for systemic antibiotic prescription and individual antibiotic choice. The role of non-antibiotic management and topical antiseptics needs to be explored further.

\section{INTRODUCTION}

Impetigo is a highly contagious superficial skin infection caused by Streptococcus pyogenes or Staphylococcus aureus. ${ }^{2}$ There are two
Strengths and limitations of this study

Large sample size.

- Data collection from diverse range of practice across all Australian states, from metropolitan to remote locations.

- No measurement of severity of impetigo.

- Insufficient power to examine associations of consultations with no antibiotic prescription.

- Insufficient power to examine the effect of Aboriginal or Torres Strait Islander ethnicity on management choice.

forms, the most common being non-bullous impetigo which presents with honey coloured crusted erosions or ulcers, typically on the face or limbs. ${ }^{12}$ Bullous impetigo is usually due to $S$. aureus $^{23}$ and presents with large fluid filled bullae typically in intertriginous areas. ${ }^{4}$ Impetigo most commonly affects children aged 0-9 years. ${ }^{125}$ In Dutch general practice the incidence of impetigo presentations is 20.6 per 1000 person years in the paediatric population. ${ }^{6}$ Impetigo prevalence is highest in humid environments and resource-poor settings where poverty, overcrowding and lack of functioning health hardware such as showers and washing machines contribute to a high burden of disease. ${ }^{12}$ The median prevalence of impetigo across studies of Australian remote dwelling Aboriginal and Torres Strait Islander populations has been estimated as $44.5 \%$ (IQR 34\%-49\%), ${ }^{1}$ with one Aboriginal medical service recording an impetigo prevalence of 7.5 per 100 consultations for localised skin infections. ${ }^{7}$ At any one time, impetigo affects 162 million children globally and 15000 Aboriginal and Torres Strait Islander children in Australia. ${ }^{1}$ The prognosis for impetigo is good and, although little objective data is available, self-resolution is thought 
to be common. ${ }^{2}$ The disease is predominantly managed in the community and rarely requires hospitalisation. ${ }^{2} 8$ Serious complications such as rheumatic fever, poststreptococcal glomerulonephritis and rheumatic heart disease generally only occur in resource-poor areas where $S$. pyogenes is the most common pathogen. ${ }^{23}$ However, given its highly contagious nature, children with impetigo are usually excluded from school until treatment has been commenced, resulting in parental loss of productivity and income. ${ }^{9}{ }^{10}$ Furthermore, as a common condition often treated with antibiotics, impetigo management has considerable antibiotic stewardship implications.

Antimicrobial resistance is a serious global threat to public health ${ }^{11} 12$ and has significant repercussions on our ability to treat impetigo effectively. Antibiotic misuse in treating impetigo may accelerate the emergence of resistant organisms. ${ }^{13}$ Early-career general practitioners (GPs) are a demographic of particular interest in this regard as antibiotic prescribing habits established early in practice may be long-lasting ${ }^{14}$ and impetigo is overwhelmingly managed in the community. ${ }^{28}$

The aim of this study was to establish the prevalence and associations of systemic antibiotic prescription (compared with solely topical antibiotic prescription) for new presentations of impetigo by early-career GPs (GP registrars in their first 18 months of general practice).

\section{METHODS}

\section{Registrar Clinical Encounters in Training study}

Registrar Clinical Encounters in Training (ReCEnT) is an ongoing multisite cohort study of Australian GP registrars' in-consultation clinical practice. Australian GP registrars are vocational trainees in general practice. These early-career GPs practice with considerable clinical autonomy with equivalent prescribing and pathology-ordering privileges to experienced colleagues. Participants in ReCEnT from 2010 were from five of Australia's then 17 Regional Training Providers (RTPs). From 2016 three of Australia's nine Regional Training Organisations in a reorganised Australian vocational training programme participated. At the time of this analysis, individual regions had contributed from two to 16 rounds of six monthly data collection. Detailed methodology for ReCEnT has been described elsewhere. ${ }^{15}$ Briefly, registrars undertake data collection once per 6-month training term (three times in the course of training). Details of 60 consecutive office-based consultations are recorded on a paper-based Case Report Form. Detailed individual feedback reports inform registrars' reflection on practice. ${ }^{16}$ Registrars may provide informed written consent for their ReCEnT data to be also used for research.

\section{Outcome factor}

In an analysis including only first presentations of impetigo for which antibiotics were prescribed, the outcome factor was 'systemic antibiotic prescribed', including coprescription with topical systemic antibiotics, versus solely topical antibiotic prescribed.

\section{Independent variables}

Independent variables related to the registrar, patient, practice and consultation.

Registrar-related variables were age, gender, training term, place of medical qualification (Australia/international), full-time/part-time status and whether they had worked at the practice in previous terms.

Patient-related variables were age, gender, Aboriginal or Torres Strait Islander status, non-English speaking background, if the problem/diagnosis was new and whether the patient was new to the practice or the registrar.

Practice variables included the training 'region', rurality/ urbanicity, practice size (number of GPs), socioeconomic status of the practice location, and if the practice routinely bulk-bills all patients (resulting in no direct financial cost to the patient for the consultation). Practice postcode was used to define the Australian Standard Geographical Classification-Remoteness Area classification (the degree of rurality) of the practice location ${ }^{17}$ and to define the practice location's Socioeconomic Index for Area Relative Index of Disadvantage. ${ }^{18}$

Consultation variables were duration of consultation (in minutes), number of diagnoses/problems recorded for the consultation, whether pathology or imaging was ordered, if specialist referral was made or follow-up was organised, and if medication was prescribed. Further consultation-related independent variables were education-related: whether the registrar sought information, advice or assistance for the problem/diagnosis (from their supervisor/trainer, from a specialist, or from electronic or hard-copy resources) and if the registrar generated personal learning goals related to the index problem/diagnosis.

\section{Statistical analysis}

This was a cross-sectional analysis of data from the ReCEnT cohort study. Analysis was at the level of the individual problem/diagnosis and performed on 16 rounds of data collected from 2010 to 2017. The proportion of registrars' problems/diagnoses that were impetigo and the proportion of consultations involving an impetigo problem/diagnosis were calculated, with 95\% CIs. For first presentations of impetigo that were prescribed antibiotics, univariate and multivariable logistic regression was conducted with outcome factor 'systemic antibiotic prescribed' versus 'solely topical antibiotic prescribed'. Logistic regression was used within the generalised estimating equations framework to account for repeated measures within registrars, an exchangeable working correlation structure was assumed.

Covariates with a univariate $\mathrm{p}$ value $<0.20$ in univariate analysis were included in the multiple regression model which was then assessed for model reduction. Covariates which were no longer significant $($ at $\mathrm{p}<0.2)$ were tested for removal from the model, and were removed only if 


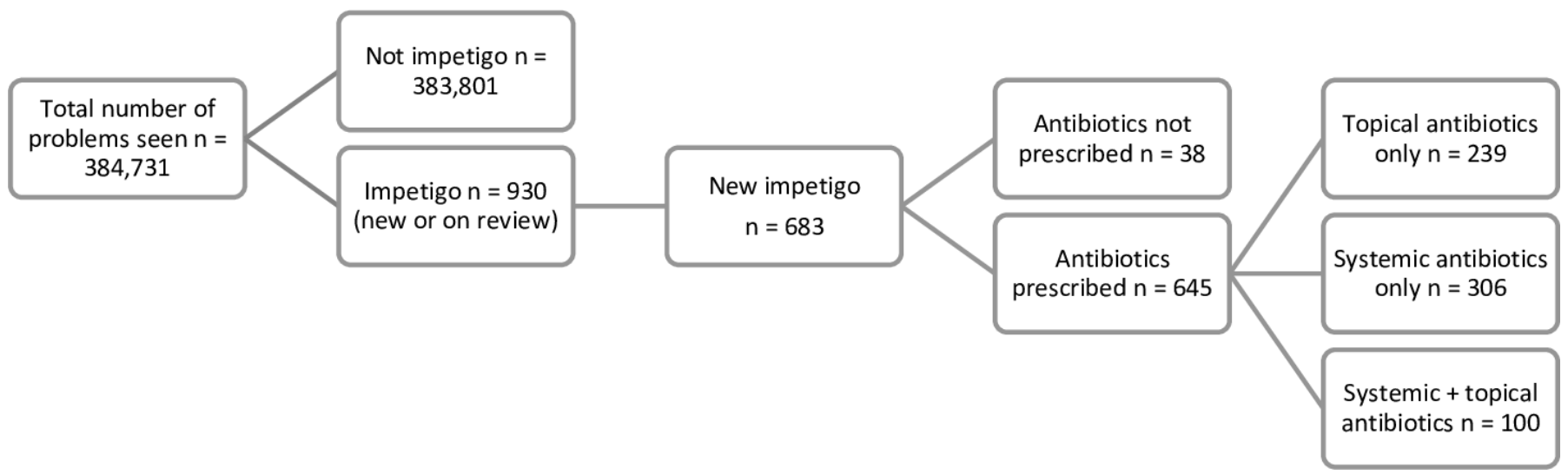

Figure 1 Prevalence and antibiotic management of impetigo.

their removal did not change other coefficient estimates by $>10 \%$. In post-hoc analyses, association of information or advice-seeking (hard copy/electronic or supervisor) with systemic antibiotic prescription was tested with $\chi^{2}$ analyses. Statistical analyses were programmed using STATA V.14.0 and SAS V.9.4. $\mathrm{P}$ values $<0.05$ were considered statistically significant.

\section{Patient and public involvement}

Patient and public were not involved in the design, conduct or reporting of research.

\section{RESULTS}

A total of 1741 GP trainees (response rate 96\%) contributed data for 384731 patient problems, from 246434 consultations. Impetigo was managed in 930 of these problems/diagnoses $(930 / 384 \quad 731,0.24 \% \quad(95 \%$ CI 0.23 to 0.26$)$ ) and comprised $0.38 \%$ of all consultations (930/246 434, $95 \%$ CI 0.35 to 0.40$)$.

Of 683 patients presenting with a new diagnosis of impetigo, 38/683 (5.6\%) were not prescribed antibiotics; 239/683 $(35.0 \%)$ were prescribed solely topical antibiotics; 306/683 (44.8\%) were prescribed solely systemic antibiotics; and 100/683 (14.6\%) were prescribed both systemic and topical antibiotics (figure 1).

Univariate associations of systemic antibiotic prescribing are summarised in table 1. In multivariate analysis, seeking in-consultation information or assistance, ordering pathology, and an inner regional (compared with a major city) practice location were significantly associated with prescribing systemic antibiotics (table 2). Patients aged 15-34 years (compared with age 65 or more) were more likely to be managed with systemic antibiotics. No variables were removed from the multiple regression model.

Cephalexin was the most frequently prescribed oral antibiotic $(215 / 406,53.0 \%)$, followed by di/flucloxacillin (154/406, $37.9 \%$ ) (figure 2). Age was recorded in $404 / 406$ consultations involving systemic antibiotics. In children under 8 years old, 112/193 (58.0\%) of systemic antibiotics prescribed were cephalexin, 60/193 (31.1\%) were flucloxacillin while no dicloxacillin (which has no subsidised liquid formulation in Australia) was prescribed.
In patients older than 8 years, $101 / 211(47.9 \%)$ were prescribed cephalexin, 76/211 $36.0 \%$ were prescribed flucloxacillin and 18/211 8.5\% were prescribed dicloxacillin. The ratio of cephalexin to influenza/dicloxacillin prescribed was1.9:1 in under 8years and 1.1:1 in older than 8 years.

Systemic antibiotic prescription that did not adhere to authoritative Australian guidelines occurred in 29/406 (7.1\%) consultations, with amoxicillin and amoxicillin/ clavulanate being most commonly prescribed. The most frequently prescribed topical antibiotic was mupirocin $(329 / 339,97.1 \%)$ (figure 2$)$. Of topical antibiotic choices, 329/339 (97.1\%) were guideline-consistent.

\section{DISCUSSION}

\section{Systemic versus topical antibiotic prescribing}

Australian early-career GPs largely managed impetigo in accordance with current Australian guidelines (box 1). However, a relatively high proportion of initial impetigo presentations $(406 / 683,59.4 \%)$ were managed with systemic antibiotics. Only $35.0 \%$ received solely topical antibiotics and only $5.6 \%$ were managed without antibiotics. This contrasts with a Dutch study where only $14 \%$ of patients with impetigo were prescribed oral antibiotics, while $64 \%$ were managed with topical antibiotics and $22 \%$ were managed without antibiotics (including $3 \%$ managed with antiseptics) ${ }^{6}$ This 2001 study also showed a trend of increasing topical antibiotic use compared with 1987 data which had found $43 \%$ topical, $31 \%$ oral and $11 \%$ antiseptic use. This difference in antibiotic prescribing may be attributable to guideline differences: at the time of this study Dutch guidelines encouraged the use of topical antibiotics first line, irrespective of impetigo severity, and also encouraged non-antibiotic treatment for limited lesions. ${ }^{6}$ The Australian guidelines currently recommend topical antibiotics for 'localised skin sores' and systemic antibiotics only for 'multiple skin sores or recurrent infection' but do not define 'localised' or 'multiple' (box 1). This lack of definition may explain high proportions of systemic antibiotic prescribing in our Australian early-career GPs. New Zealand (NZ) guidelines provide clear 
Table 1 Characteristics of patient presenting with impetigo with antibiotic prescribed

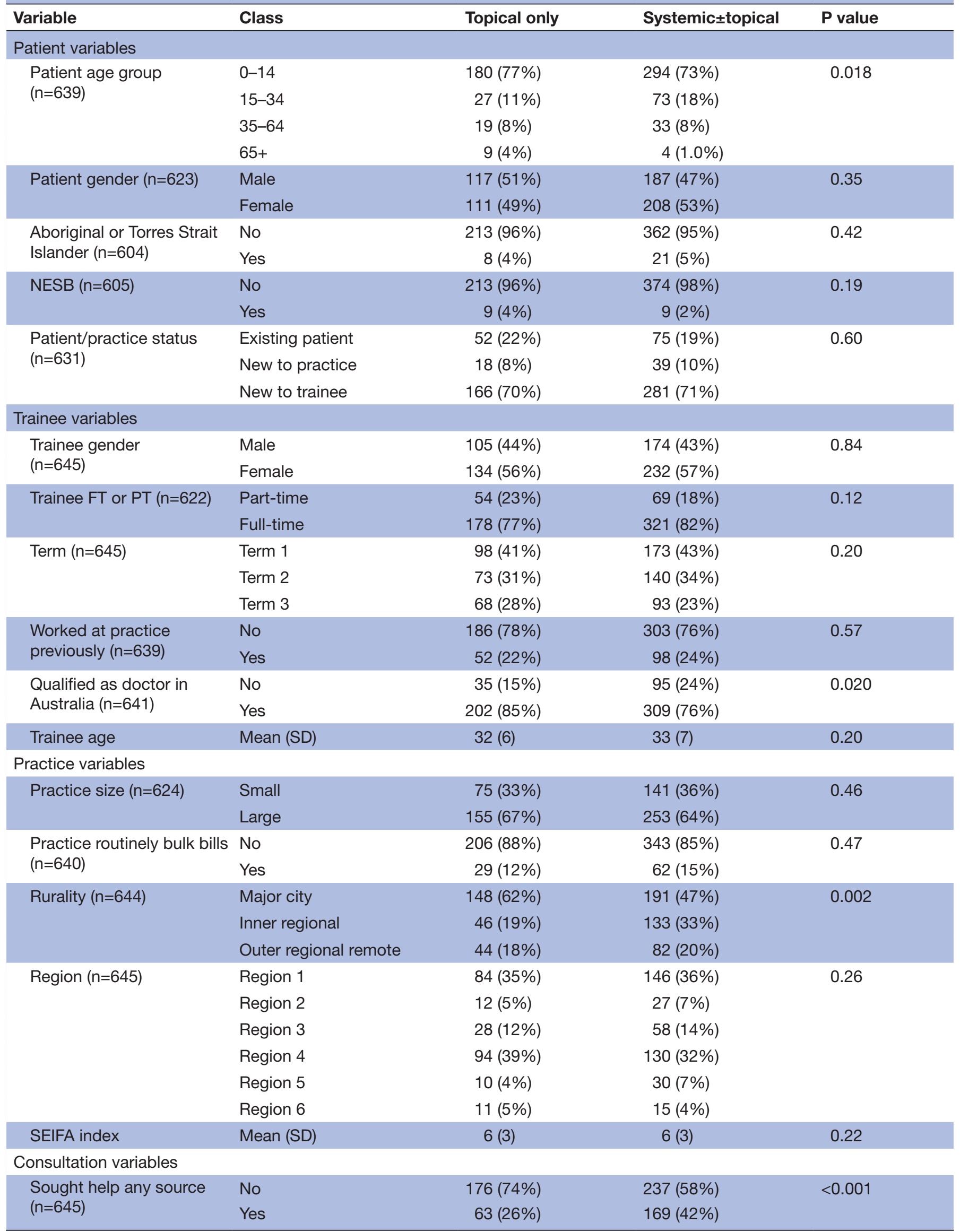




\begin{tabular}{|c|c|c|c|c|}
\hline Variable & Class & Topical only & Systemic \pm topical & $P$ value \\
\hline Consultation duration & Mean (SD) & $14(6)$ & $14(6)$ & 0.60 \\
\hline Number of problems & Mean (SD) & $1(1)$ & $1(1)$ & 0.030 \\
\hline \multicolumn{5}{|c|}{ Consultation outcome variables } \\
\hline Pathology ordered $(n=645)$ & No & $210(88 \%)$ & $308(76 \%)$ & 0.001 \\
\hline \multirow{2}{*}{$\begin{array}{l}\text { Learning goals generated } \\
(\mathrm{n}=614)\end{array}$} & No & $192(85 \%)$ & $321(83 \%)$ & 0.27 \\
\hline & Yes & $33(15 \%)$ & $68(17 \%)$ & \\
\hline \multirow[t]{2}{*}{ Follow-up ordered $(n=645)$} & No & $151(63 \%)$ & $243(60 \%)$ & 0.38 \\
\hline & Yes & 88 (37\%) & $163(40 \%)$ & \\
\hline
\end{tabular}

$P$ values from unadjusted generalised estimating equations analysis.

Region is derived from former Regional Training Provider and current Regional Training Organisation geographic footprints.

FT, full time;NESB, non-English speaking background; PT, part time;SEIFA, Socioeconomic Indexes of Areas.

definitions, recommending oral antibiotics for systemic symptoms (fever, malaise), high risk of complications, not responding to first line treatment or where there are more than three lesions. ${ }^{19}{ }^{20}$ While international guidelines display congruence in recommending oral antibiotics for systemic symptoms and failure of first-line treatment; definitions of severity employ vague terms such as 'localised, extensive, numerous lesions or widespread, $320-24$ (table 3). This lack of clarity allows room for significant subjectivity and variation in clinical decision-making, potentially compromising antibiotic stewardship.
Topical antibiotics for localised lesions are as efficacious as oral antibiotics ${ }^{25}$ and thus preferred by many guidelines because of their lower potential for antimicrobial resistance and systemic side effects. ${ }^{26}$ However with increasing resistance to topical antibiotics ${ }^{27-34}$ and increasing community methicillin resistant $S$. aureus rates, ${ }^{35-37}$ antibiotic guidelines should reflect local resistance profiles. ${ }^{25} 38 \mathrm{NZ}$ guidelines differ in their response to topical resistance by discouraging the use of topical antibiotics and instead recommending good skin hygiene and topical antiseptics ${ }^{19}{ }^{20}$ (table 3 ).

Table 2 Associations with a new diagnosis of impetigo with systemic \pm topical antibiotics prescribed (compared with topical only)

\begin{tabular}{|c|c|c|c|c|c|}
\hline Variable & Class & $\begin{array}{l}\text { Univariate OR } \\
(95 \% \mathrm{Cl})\end{array}$ & $P$ value & Adjusted OR (95\% CI) & $P$ value \\
\hline \multicolumn{6}{|c|}{ Patient, registrar and practice variables } \\
\hline \multirow{2}{*}{$\begin{array}{l}\text { Patient age group } \\
\text { (Referent: 15-34) }\end{array}$} & $35-64$ & 0.64 (0.32 to 1.28$)$ & 0.20 & $0.74(0.32$ to 1.69$)$ & 0.48 \\
\hline & $65+$ & 0.15 (0.04 to 0.53$)$ & 0.003 & $0.08(0.01$ to 0.44$)$ & 0.004 \\
\hline $\begin{array}{l}\text { Qualified as doctor in } \\
\text { Australia }\end{array}$ & Yes & 0.58 (0.36 to 0.92$)$ & 0.020 & 0.68 (0.38 to 1.22$)$ & 0.19 \\
\hline \multirow{2}{*}{$\begin{array}{l}\text { Rurality } \\
\text { (Referent: major city) }\end{array}$} & Inner regional & 2.22 (1.43 to 3.45$)$ & $<0.001$ & $1.82(1.06$ to 3.13$)$ & 0.028 \\
\hline & Outer regional remote & 1.45 (0.92 to 2.27$)$ & 0.11 & 1.25 (0.74 to 2.08$)$ & 0.41 \\
\hline \multicolumn{6}{|c|}{ Consultation outcome variables } \\
\hline Pathology ordered & Yes & 2.13 (1.37 to 3.33$)$ & 0.001 & 1.89 (1.16 to 3.03$)$ & 0.010 \\
\hline
\end{tabular}

FT, full time; NESB, non-English speaking background; PT, part time. 


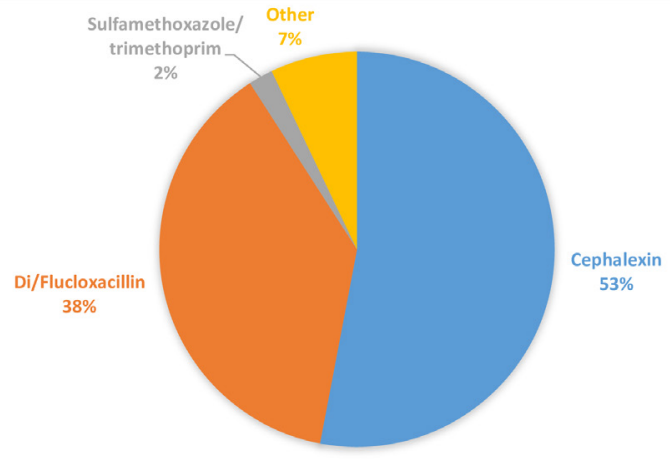

Figure 2 Systemic antibiotic prescription.

\section{Experience levels}

A factor that may contribute to the comparatively high proportion of systemic antibiotic use is the difference in level of experience between Australian GP registrars (early in their GP careers) and the established GPs involved in the 2001 Dutch study. ${ }^{6}$ Previous studies have shown that GP registrars find dermatological presentations challenging despite having adequate exposure to dermatological cases. ${ }^{39}$ Additionally, registrars in a qualitative study reported prescribing antibiotics as "playing it safe' early in their clinical experience but being less likely to prescribe with increasing time and confidence. ${ }^{40}$ Our early-career GPs who prescribed systemic antibiotics were more likely to seek information or advice either from their supervisor or from guidelines. As we do not have a measure of impetigo severity in our data it is difficult to ascertain whether seeking advice from a supervisor is a risk factor for prescribing antibiotics, or whether this reflects appropriate practice -information/advice being sought for more severe disease warranting antibioticsby registrars. Information-seeking may also have been to check dosing, particularly in paediatric patients. Ensuring adherence to appropriate treatment and responsible prescribing of antimicrobials in this cohort is important as GP registrars in Australia have the same prescribing rights as established GP's and work independently,

\section{Box 1 Australian therapeutic guidelines for impetigo ${ }^{3}$}

For localised skin sores, recommendation is:

- Mupirocin $2 \%$ ointment.

For multiple impetigo lesions or recurrent infection, recommendation is: - Di/flucloxacillin.

Cephalexin, though, may be used for patients with non-immediate hypersensitivity to penicillins or in children due to greater tolerability and better palatability of liquid formula.

For patients with anaphylaxis to penicillins, the recommendation is:

- Trimethoprim+sulfamethoxazole.

The Therapeutic Guidelines make specific reference to different management recommendations for impetigo in remote Aboriginal and Torres Strait Islander communities: "First line treatment is trimethoprim plus sulfamethoxazole or intramuscular benzathine penicillin; topical antibiotics are not recommended". with direct supervision only when requested. There is evidence that antibiotic prescribing patterns developed earlier in GPs' careers remain stable over time. ${ }^{14}$ Therefore, instilling values of antimicrobial stewardship and rational prescribing in early-career doctors has significant implications for future practice.

\section{Dual prescription of topical and systemic antibiotics}

Australian early career GPs prescribed both topical and systemic antibiotics in 100/683 (14.6\%) of new impetigo cases, despite there being no evidence to support combined use $\mathrm{e}^{25}$ and no recommendation in guidelines. ${ }^{30-24}$ This may indicate confusion in the management of impetigo which may be avoided if combined treatment were specifically addressed in guidelines.

\section{Broad spectrum antibiotic prescribing}

Despite di/flucloxacillin being recommended as first line systemic antibiotic for treatment of impetigo, ${ }^{3}$ the most frequently prescribed antibiotic was cephalexin. It is unlikely that penicillin allergy is the sole explanation. ${ }^{41}$ Australian guidelines for impetigo comment that cephalexin may be used instead of flucloxacillin for children 'due to greater tolerability and better palatability of the liquid formulation'. ${ }^{3}$ Though medication compliance is important, this 'escape' clause in Australia may foster a culture that allows unnecessary broad-spectrum antibiotic prescription simply because it is 'easier' than using appropriate narrow-spectrum treatment. We found a preference for cephalexin rather than di/flucloxacillin even in patients older than 8 years. In contrast, most European guidelines and the $\mathrm{NZ}$ guidelines do not recommend cephalexin. ${ }^{20-22} 24$ UK figures show less than $2 \%$ of cephalexin prescriptions were for skin infections and cephalexin was used to treat only $1 \%$ of impetigo cases, with flucloxacillin usually prescribed. ${ }^{42}$ This perhaps indicates that perceived barriers to compliance can be overcome. In addition to modifying guidelines, clinicians in Australia could work collaboratively with pharmaceutical companies to develop more palatable narrow spectrum antibiotics options.

\section{Topical antiseptics}

A 2012 Cochrane review found insufficient evidence to support the use of topical antiseptics for impetigo. ${ }^{25}$ Pooling of two low-quality studies ${ }^{43} 44$ with a total of 292 participants showed marginal superiority of topical antibiotics compared with antiseptics (risk ratio (RR) 1.15 $95 \%$ CI 1.01 to 1.32 ). Guidelines appear to differ in their interpretation of this paucity of evidence, either stating antiseptics are not recommended, ${ }^{22-24}$ encouraging their use ${ }^{20}$ or not mentioning them at all ${ }^{3}$ (table 3). Only $3.5 \%$ of cases in our study were managed without antibiotics and given concerns regarding growing resistance to topical and oral antibiotics used for impetigo, further studies to clarify the efficacy and potential role of topical antiseptics are required. Given the modest consequences of failed treatment, recommending the use of topical 
Table 3 Comparison of international guidelines for management of impetigo

\begin{tabular}{|c|c|c|c|c|}
\hline Country, year & $\begin{array}{l}\text { Advice on } \\
\text { antiseptics }\end{array}$ & $\begin{array}{l}\text { Topical antibiotic } \\
\text { indications and } \\
\text { recommendations }\end{array}$ & $\begin{array}{l}\text { Oral antibiotic indications and } \\
\text { recommendations }\end{array}$ & $\begin{array}{l}\text { Skin swab } \\
\text { indications }\end{array}$ \\
\hline $\begin{array}{l}\text { Australia, } \\
2017^{3}\end{array}$ & Not specified. & $\begin{array}{l}\text { 'Localised lesions': } \\
\text { Mupirocin. } \\
\text { 'Remote setting': } \\
\text { Topical treatment not } \\
\text { recommended. }\end{array}$ & $\begin{array}{l}\text { 'Multiple lesions, recurrent infection': } \\
\text { Di/flucloxacillin. } \\
\text { Penicillin allergy: } \\
\text { Cephalexin or trimethoprim } \\
\text { +sulfamethoxazole. } \\
\text { 'Remote settings': } \\
\text { Benzathine penicillin or trimethoprim- } \\
\text { sulfamethoxazole. }\end{array}$ & $\begin{array}{l}\text { Only for severe } \\
\text { disease or no } \\
\text { response to } \\
\text { empirical treatment. }\end{array}$ \\
\hline UK, $2015^{22}$ & $\begin{array}{l}\text { Antiseptics should } \\
\text { not be used due } \\
\text { to risk of local } \\
\text { reaction, and not } \\
\text { recommended due to } \\
\text { lack of evidence. }\end{array}$ & $\begin{array}{l}\text { 'Localised lesions': } \\
\text { Fusidic acid. } \\
\text { Mupirocin reserved for } \\
\text { known MRSA. } \\
\text { Retapamulin second } \\
\text { line as more costly than } \\
\text { fusidic acid. }\end{array}$ & $\begin{array}{l}\text { 'Extensive areas': } \\
\text { Flucloxacillin. } \\
\text { Penicillin allergy: } \\
\text { Clarithromycin or erythromycin. }\end{array}$ & $\begin{array}{l}\text { Empirical treatment } \\
\text { failure. }\end{array}$ \\
\hline $\begin{array}{l}\text { Netherlands, } \\
2017^{24}\end{array}$ & $\begin{array}{l}\text { Use of antiseptics or } \\
\text { disinfectants is not } \\
\text { recommended. }\end{array}$ & $\begin{array}{l}\text { 'First choice': } \\
\text { Fusidic acid. }\end{array}$ & $\begin{array}{l}\text { 'If insufficient response': } \\
\text { Flucloxacillin. } \\
\text { Penicillin allergy clarithromycin or } \\
\text { clindamycin. }\end{array}$ & $\begin{array}{l}\text { Additional } \\
\text { diagnostics not } \\
\text { needed unless: } \\
\text { Increased risk } \\
\text { Methicillin-resistant } \\
\text { Stpahylococcal } \\
\text { aureus (MRSA) or } \\
\text { screening for S. } \\
\text { aureus carrier or } \\
\text { suspected abscess. }\end{array}$ \\
\hline $\begin{array}{l}\text { New Zealand, } \\
2017^{20}\end{array}$ & $\begin{array}{l}\text { For localised lesions } \\
(\leq 3)^{\prime} \text { : hydrogen } \\
\text { peroxide } 1 \% \text { or } \\
\text { povidone-iodine } \\
10 \% .\end{array}$ & $\begin{array}{l}\text { 'For localised infection, } \\
\text { second line to topical } \\
\text { antiseptics': Fusidic acid } \\
\text { Not first line as high } \\
\text { rates of resistance. }\end{array}$ & $\begin{array}{l}\text { Extensive, widespread infection; } \\
\text { systemic symptoms': } \\
\text { Flucloxacillin. } \\
\text { 'Penicillin allergy or MRSA': } \\
\text { Trimethoprim+sulfamethoxazole or } \\
\text { erythromycin. }\end{array}$ & Not specified. \\
\hline
\end{tabular}

antiseptics for limited lesions may be reasonable as first line management.

\section{Strengths and limitations}

ReCEnt study data includes a large sample of GP registrars from across diverse regions of Australia, from major cities to very remote areas. It is the largest database of clinical encounters of early-career GPs in Australia.

There are limitations to the analysis and interpretation of these data. We do not have data on severity, including number of lesions, or of history of recurrent disease. No system for grading severity was used in this study, which is reflective of the lack of severity criteria seen in most guidelines (table 3 ). With this lack of consensus in guidelines there would have been little evidence base for a severity grading system in our study. There was insufficient power to examine associations of consultations with no antibiotic prescription. The low number of Aboriginal or Torres Strait Islander patients $(4 \%)$ limited our power to measure the effect of this important patient demographic on management choice.

\section{Implications for future research}

Concerns regarding antimicrobial resistance justify investigation into alternative topical treatments. ${ }^{45}$ Further investigation into topical antiseptics could bring greater congruence to international guidelines and potentially encourage non-antibiotic treatment of impetigo, particularly for single or limited lesions. Despite evidence that complementary treatments such as tea tree oil are effective against $S$. aureus, ${ }^{46}$ objective evidence for use in treating impetigo is lacking and they are currently not recommended in guidelines. However, scarce data for non-antibiotic treatments is promising and warrants further investigation. ${ }^{25}$ Novel topical antibiotic agents such as ozenoxacin and retapamulin have been shown 
to be effective in treating impetigo, ${ }^{47} 48$ but should be reserved for resistant strains until there is further research in this area.

\section{CONCLUSION}

Appropriate use of antibiotics is of utmost importance in the management of impetigo. Our findings show that Australian early-career GPs use more systemic antibiotics and more broad-spectrum antibiotics compared with colleagues in other settings. More clarity of guidelines, including criteria for severity of disease, could steer towards more appropriate use. Exploration of non-antibiotic management options is an important area for future research.

\section{Author affiliations}

${ }^{1}$ School of Medicine and Dentistry, James Cook University, Mackay, Queensland, Australia

${ }^{2}$ Department of General Practice and Rural Medicine, James Cook University, Mackay, Queensland, Australia

${ }^{3}$ Academic Discipline of General Practice, University of Queensland, Brisbane, Queensland, Australia

${ }^{4}$ NSW \& ACT Research and Evaluation Unit, GP Synergy Ltd - Newcastle, Newcastle, New South Wales, Australia

${ }^{5}$ Discipline of General Practice, School of Medicine \& Public Health, University of Newcastle, Callaghan, New South Wales, Australia

${ }^{6} \mathrm{Global}$ and Tropical Health Division, Menzies School of Health Research, Casuarina, New South Wales, Australia

${ }^{7}$ GP Synergy Ltd, Liverpool Westfield, New South Wales, Australia

${ }^{8}$ The University of Newcastle, Newcastle, New South Wales, Australia

${ }^{9}$ Clinical Research Design and Statistics, The University of Newcastle Hunter

Medical Research Institute, New Lambton, New South Wales, Australia

${ }^{10}$ Eastern Victoria General Practice Training, Melbourne, Victoria, Australia

${ }^{11}$ University of Melbourne, Melbourne, Victoria, Australia

${ }^{12}$ General Practice Training Tasmania, Hobart, Tasmania, Australia

${ }^{13}$ Discipline of General Practice, University of Newcastle, Callaghan, New South Wales, Australia

Contributors $\mathrm{CH}$ and $\mathrm{HG}$ led the design of this study, the interpretation of the results and the development of the manuscript. HG, MLvD and PM, assisted with the design of the study and the interpretation of results and the development of the manuscript. PM and MLvD led the ReCEnT study. AT was responsible for statistical analysis and assisted in data collection and data entry. JD, AD, LH, NS, KF, JB and NN were co-investigators of the ReCENT study. All authors contributed to the revision and editing of the manuscript. The corresponding author attests that all listed authors meet authorship criteria and that no others meeting the criteria have been omitted. $\mathrm{CH}$ and $\mathrm{HG}$ are equal first name authors of the manuscript.

Funding During the data collection period included in this study, from 2010 to 2015 funding of the ReCEnT study was by the participating educational organisations: General Practice Training Valley to Coast, the Victorian Metropolitan Alliance, General Practice Training Tasmania, Tropical Medical Training and Adelaide to Outback GP Training Program. These organisations were funded by the Australian Department of Health. Since 2016, the ReCEnT study is funded by an Australian Commonwealth Department of Health Research Grant and supported by GP Synergy, the general practice Regional Training Organisation for New South Wales and the Australian Capital Territory. GP Synergy is funded by the Australian Department of Health. The Researchers were independent from funders and all authors had full access to all of the data in the study and can take responsibility for the integrity of the data and the accuracy of the data analysis.

Competing interests None declared.

Patient consent for publication Not required.

Ethics approval The ReCEnT project has approval from the University of Newcastle Human Research Ethics Committee, Reference H-2009-0323.

Provenance and peer review Not commissioned; externally peer reviewed.
Data availability statement Data are available upon reasonable request.

Open access This is an open access article distributed in accordance with the Creative Commons Attribution Non Commercial (CC BY-NC 4.0) license, which permits others to distribute, remix, adapt, build upon this work non-commercially, and license their derivative works on different terms, provided the original work is properly cited, appropriate credit is given, any changes made indicated, and the use is non-commercial. See: http://creativecommons.org/licenses/by-nc/4.0/.

\section{ORCID iDs}

Hilary Gorges http://orcid.org/0000-0002-0943-1590

Mieke L van Driel http://orcid.org/0000-0003-1711-9553

Parker Magin http://orcid.org/0000-0001-8071-8749

\section{REFERENCES}

1 Bowen AC, Mahé A, Hay RJ, et al. The global epidemiology of impetigo: a systematic review of the population prevalence of impetigo and pyoderma. PLoS One 2015;10:e0136789.

2 WHO. Epidemiology and management of common skin diseases in children in developing countries, 2005. Available: http://www.who.int/ maternal_child_adolescent/documents/fch_cah_05_12/en/

3 eTG. Electronic therapeutic guidelines complete: impetigo, 2018. Available: https://tgldcdp.tg.org.au/viewTopic?topicfile=skin-softtissue-infections-bacterial\&guidelineName=Antibiotic\#toc_d1e1116

4 Hartman-Adams H, Banvard C, Juckett G. Impetigo: diagnosis and treatment. Am Fam Physician 2014;90:229-35.

5 Sladden MJ, Johnston GA. Common skin infections in children. BMJ 2004;329:95-9.

6 Koning S, Mohammedamin RSA, van der Wouden JC, et al. Impetigo: incidence and treatment in Dutch general practice in 1987 and 2001--results from two national surveys. Br J Dermatol 2006;154:239-43.

7 Thomas DP, Heller RF, Hunt JM. Clinical consultations in an Aboriginal community-controlled health service: a comparison with general practice. Aust N Z J Public Health 1998;22:86-91.

8 Shallcross LJ, Petersen I, Rosenthal J, et al. Use of primary care data for detecting impetigo trends, United Kingdom, 1995-2010. Emerg Infect Dis 2013;19:1646-8.

9 Hay RJ, Estrada Castanon R, Alarcon Hernandez H, et al. Wastage of family income on skin disease in Mexico. BMJ 1994;309:848.

10 NHMRC. Staying healthy: preventing infectious diseases in early childhood education and care services, 2012. Available: http://www. imagineeducation.com.au/files/GapTraining/Staying_Healthy_5th_ Edition.pdf

11 WHO. Antimicrobial resistance: fact sheet No. 194, 2018. Available: http://www.who.int/news-room/fact-sheets/detail/antimicrobialresistance

12 O'Neill J. Review on antimicrobial resistance: tackling drug-resistant infections globally, 2016

13 WHO. Worldwide country situation analysis: response to antimicrobial resistance, 2015. Available: http://apps.who.int/iris/ bitstream/handle/10665/163473/WHO_HSE_PED_AIP_2015.1 eng.pdf;jsessionid=D5BFEB02EF1DA68E4799ED91D2D5BDE3? sequence $=1$

14 Björnsdóttir I, Kristinsson KG, Hansen EH. Diagnosing infections: a qualitative view on prescription decisions in general practice over time. Pharm World Sci 2010;32:805-14

15 Morgan S, Magin PJ, Henderson KM, et al. Study protocol: the registrar clinical encounters in training (recent) study. BMC Fam Pract 2012:13:50.

16 Magin P, Morgan S, Henderson K, et al. The registrars' clinical encounters in training (recent) project: educational and research aspects of documenting general practice trainees' clinical experience. Australian Family Physician 2015;44:681-4.

17 ABS. Australian Bureau of statistics: Australian standard geographical classification (ASGC), 2006. Available: http://www.abs. gov.au/AUSSTATS/abs@.nsf/Latestproducts/1AE106C101420508 CA2571A900170741

18 ABS. Australian Bureau of Statistics - Information Paper: An Introduction to Socioeconomic Indexes of Areas (SEIFA), 2006. Available: http://www.abs.gov.au/ausstats/abs@.nsf/mf/2039.0/

19 DermNet. Impetigo, 2015. Available: https://www.dermnetnz.org/ topics/impetigo/

20 BPAC. Antibiotics: choices for common infections. impetigo, 2017. Available: https://bpac.org.nz/antibiotics/guide.aspx\#impetigo

21 van Bijnen EME, Paget J, den Heijer CDJ, et al. Evidence-Based primary care treatment guidelines for skin infections in Europe: 
a comparative analysis. European Journal of General Practice 2014;20:294-300.

22 Impetigo N, 2015. Available: https://cks.nice.org.uk/

23 IDSA. Practice guidelines for the diagnosis and management of skin and soft tissue infections: 2014 update by the infectious diseases Society of America, 2014. Available: https://academic.oup.com/cid/ article/59/2/e10/2895845

24 NHG. NHG-Standaard Bacteriële huidinfecties. Available: https:// www.nhg.org/standaarden/volledig/nhg-standaard-bacterielehuidinfecties

25 Koning S, van der Sande R, Verhagen AP, et al. Interventions for impetigo. Cochrane Database Syst Rev 2012;1.

26 Lio PA, Kaye ET. Topical antibacterial agents. Med Clin North Am 2011;95:703-21.

27 Antonov NK, Garzon MC, Morel KD, et al. High prevalence of mupirocin resistance in Staphylococcus aureus isolates from a pediatric population. Antimicrob Agents Chemother 2015;59:3350-6.

28 Lee AS, Macedo-Vinas M, François P, et al. Impact of combined low-level mupirocin and genotypic chlorhexidine resistance on persistent methicillin-resistant Staphylococcus aureus carriage after decolonization therapy: a case-control study. Clin Infect Dis 2011;52:1422-30.

29 Deshpande LM, Fix AM, Pfaller MA, et al. Emerging elevated mupirocin resistance rates among staphylococcal isolates in the SENTRY antimicrobial surveillance program (2000): correlations of results from disk diffusion, Etest and reference dilution methods. Diagn Microbiol Infect Dis 2002;42:283-90.

30 Williamson DA, Monecke $\mathrm{S}$, Heffernan $\mathrm{H}$, et al. High usage of topical fusidic acid and rapid clonal expansion of fusidic AcidResistant Staphylococcus aureus: a cautionary tale. Clin Infect Dis 2014;59:1451-4.

31 Howden BP, Grayson ML. Dumb and dumber--the potential waste of a useful antistaphylococcal agent: emerging fusidic acid resistance in Staphylococcus aureus. Clin Infect Dis 2006;42:394-400.

32 Heng YK, Tan KT, Sen P, et al. Staphylococcus aureus and topical fusidic acid use: results of a clinical audit on antimicrobial resistance. Int J Dermatol 2013;52:876-81.

33 Vogel A, Lennon D, Best E, et al. Where to from here? the treatment of impetigo in children as resistance to fusidic acid emerges. $N Z$ Med J 2016;129:77-83.

34 Williamson DA, Carter GP, Howden BP. Current and emerging topical antibacterials and antiseptics: agents, action, and resistance patterns. Clin Microbiol Rev 2017;30:827-60.
35 Tong SYC, Varrone L, Chatfield MD, et al. Progressive increase in community-associated methicillin-resistant Staphylococcus aureus in Indigenous populations in northern Australia from 1993 to 2012. Epidemiol Infect 2015;143:1519-23.

36 Munckhof WJ, Schooneveldt J, Coombs GW, et al. Emergence of community-acquired methicillin-resistant Staphylococcus aureus (MRSA) infection in Queensland, Australia. Int J Infect Dis 2003;7:259-67.

37 Gosbell IB, Mercer JL, Neville SA, et al. Non-Multiresistant and multiresistant methicillin-resistant Staphylococcus aureus in community-acquired infections. Med J Aust 2001;174:627-30.

38 Bangert S, Levy M, Hebert AA. Bacterial resistance and impetigo treatment trends: a review. Pediatr Dermatol 2012;29:243-8.

39 Whiting G, Magin P, Morgan S, et al. General practice trainees' clinical experience of dermatology indicates a need for improved education: a cross-sectional analysis from the registrar clinical encounters in training study. Australas J Dermatol 2017;58:e199-206.

40 Dallas A, van Driel M, van de Mortel T, et al. Antibiotic prescribing for the future: exploring the attitudes of trainees in general practice. $\mathrm{Br} \mathrm{J}$ Gen Pract 2014;64:e561-7.

41 Graff-Lonnevig V, Hedlin G, Lindfors A. Penicillin allergy--a rare paediatric condition? Arch Dis Child 1988;63:1342-6.

42 Petersen IHayward AC, Subgroup SS, SACAR Surveillance Subgroup. Antibacterial prescribing in primary care. J Antimicrob Chemother 2007;60 Suppl 1:i43-7.

43 Christensen OB, Anehus S. Hydrogen peroxide cream: an alternative to topical antibiotics in the treatment of impetigo contagiosa. Acta Derm Venereol 1994;74:460-2.

44 Ruby RJ, Nelson JD. The influence of hexachlorophene scrubs on the response to placebo or penicillin therapy in impetigo. Pediatrics 1973;52:854-9.

45 D'Cunha NM, Peterson GM, Baby KE, et al. Impetigo: a need for new therapies in a world of increasing antimicrobial resistance. J Clin Pharm Ther 2018:43:150-3.

46 Kwieciński J, Eick S, Wójcik K. Effects of tea tree (Melaleuca alternifolia) oil on Staphylococcus aureus in biofilms and stationary growth phase. Int J Antimicrob Agents 2009;33:343-7.

47 Oranje AP, de Waard-van der Spek FB. Recent developments in the management of common childhood skin infections. J Infect 2015;71:S76-9.

48 Rosen T, Albareda N, Rosenberg N, et al. Efficacy and safety of Ozenoxacin cream for treatment of adult and pediatric patients with impetigo: a randomized clinical trial. JAMA Dermatol 2018;154:806-13. 